\title{
Short communication: Entrapment of Listeria cells within air pockets of ice cream mix matrix may lead to potentially heat-injured cells
}

\author{
Neha Neha and Sanjeev Anand* \\ Midwest Dairy Foods Research Center, Dairy and Food Science Department, South Dakota State University, Brookings 57007
}

\section{ABSTRACT}

In our previous study, we observed the sporadic presence of potentially heat-injured cells of Listeria innocua in ice cream mix following a selective enrichment protocol. Although injured cells have not yet been reported to cause any disease outbreaks, it is important to understand their presence in heat-treated food matrices. In this study, we propose a possible protective role of air pockets that may help explain the sporadic presence of potentially heat-injured cells following heat treatment. Challenge studies were conducted by inoculating ice cream mix samples ( $42 \%$ total solids, $16.3 \%$ fat, $22.2 \%$ total sugar, and $3.4 \%$ protein) with Listeria innocua (an established surrogate) at a mean spiking level of $4.0 \log \mathrm{cfu} / \mathrm{g}$. The inoculated samples were heat-treated at $69^{\circ} \mathrm{C}$ for $30 \mathrm{~min}$ and potentially heatinjured cells were detected using buffered Listeria enrichment broth, followed by plating on modified Oxford and Rapid'LMono agars. Scanning electron microscopy and atomic force microscopy were conducted on the airdried, spiked ice cream mix samples, before and after the thermal treatment stages. Although direct plating did not reveal any intact cells in the heat-treated ice cream mix, a more sensitive enrichment protocol was able to identify cells that were potentially heat-injured. The scanning electron micrographs showed air pockets of different sizes in the ice cream mix samples. The spiked mix samples before heat treatment showed some Listeria cells unevenly distributed in the mix matrix and some entrapped within the larger air pockets. After heat treatment, scanning electron and atomic force micrographs showed cells entrapped only within the larger air pockets. The mix matrix, however, did not show any Listeria cells. Confirmation of Listeria at all stages of analysis was done using MALDI-TOF. These observations suggest that the Listeria cells could be entrapped within the larger air pockets and thus may undergo

Received August 20, 2018.

Accepted July 2, 2019.

*Corresponding author: Sanjeev.anand@sdstate.edu inadequate thermal effect. This could have resulted in their detection as potentially heat-injured cells, as evident under the conditions of the experiment. These results are preliminary observations and further studies are necessary to draw conclusions and understand the true implications of these findings.

Key words: injured cells, ice cream, air pocket, Listeria

\section{Short Communication}

Listeria monocytogenes is an important food-borne pathogen that is frequently associated with recall of frozen products, including ice cream. According to Centers for Disease Control and Prevention (CDC), there were 9 Listeria-related ice cream recalls during 2014/2015. An ice cream-related outbreak in March 2015 resulted in 10 hospitalizations and 3 deaths. In April 2015 (CDC, 2015), another commercial ice cream tested positive for $L$. monocytogenes and the manufacturer recalled all the products (FDA, 2015). In 2017, a voluntary recall of all orange cream bars and chocolate-coated vanilla ice cream bars was reported because of the possibility of contamination with Listeria monocytogenes (FDA, 2018). Post-processing environmental contamination was the likely cause of these cases. However, the possibility exists for cells to become injured due to a sublethal thermal effect when heat-treated at $69^{\circ} \mathrm{C}$ for $30 \mathrm{~min}$. Of the reasons linked to potential survival, the intracellular packaging of some Listeria spp. within leukocytes has been reported to result in inadequate pasteurization effect, leading to the presence of intracellular lipid-shielded cells (Bearns and Girard, 1958). Similarly, the significance of a large inoculum size on the potential survival of organisms during pasteurization has been reported (Farber et al., 1988). It may not always be feasible to eliminate all bacteria with thermal treatment (Besse 2002). The physiological stress caused by heating might also lead to injured cells that could repair themselves when subjected to favorable conditions (McMahon et al., 2000; Besse 2002). Doyle et al. (1987) reported that L. monocytogenes, residing within polymorphonuclear leukocytes in the milk of Listeria-infected cows, could 
withstand thermal treatment of $72.2^{\circ} \mathrm{C}$ for $16.4 \mathrm{~s}$ in an HTST pasteurizer. While discussing the adequacy of pasteurization, Lou and Yousef (1999) mentioned that "pasteurization is a safe process, which reduces the number of $L$. monocytogenes occurring in raw milk to levels that do not pose an appreciable risk to human health." They also noted that "although minimum HTST milk pasteurization is considered a safe process, most raw milk processing facilities have wisely adopted pasteurization temperatures well above the minimum legal limit." Similarly, in a previous study in our laboratory (Neha et al., 2018), we observed the sporadic presence of potentially heat-injured cells of Listeria in ice cream mix heat-treated at $69^{\circ} \mathrm{C}$ for $30 \mathrm{~min}$. In addition to the factors discussed above, some currently unrecognized mechanisms might lead to potentially heat-injured cells in thermally treated products such as ice cream. In view of this, we investigated a possible protective role of air pockets that could explain the sporadic presence of potentially heat-injured cells in ice cream mix under simulated conditions.

Raw ice cream mix samples ( $42 \%$ total solids, $16.3 \%$ fat, $22.2 \%$ total sugar, and $3.4 \%$ protein) were obtained in 3.76-L packs, in temperature-controlled containers, from a commercial ice cream manufacturer. These were analyzed, upon receipt, for background bacterial counts and chemical parameters such as water activity and $\mathrm{pH}$ using standard methods, as explained in our previous paper (Neha et al., 2018). A pure culture of Listeria innocua (ATCC 33090) was procured from American Type Culture Collection (Manassas, VA). This is a nonpathogenic thermal processing surrogate of L. monocytogenes, and has previously been used in thermal resistance studies (Ryser and Marth, 1999; Kozempel et al., 2000; Li et al., 2013). The culture was activated in brain heart infusion (BHI) broth (Oxoid/ Thermo Scientific, Basingstoke, UK) and incubated at $37^{\circ} \mathrm{C}$ for $24 \mathrm{~h}$. For challenge studies, ice cream mix samples were tempered to $40^{\circ} \mathrm{C}$ in a water bath (Wehr and Frank, 2004) and inoculated at an average dose level of $\log 4.0 \mathrm{cfu} / \mathrm{g}$ of $L$. innocua-activated culture. After $6 \mathrm{~h}$ of growth, the culture (mid exponential cells) was centrifuged $\left(2,000 \times g\right.$ for $15 \mathrm{~min}$ at $\left.4^{\circ} \mathrm{C}\right)$ and washed twice with PBS to harvest the cells (Neha et al., 2018). Appropriate cell suspensions were made by diluting the harvested cells in PBS to obtain log $4.0 \mathrm{cfu} / \mathrm{g}$ spiking levels in ice cream mix samples. The spiked ice cream mix samples (90 g each) in enclosed borosilicate glass bottles (125 mL; DWK Life Sciences Inc., Millville, NJ) were heat-treated at $69^{\circ} \mathrm{C}$ for 30 min in a shaker water bath at $70 \mathrm{rpm}$ (Lab Companion reciprocal shaking water bath, Cole-Parmer, Vernon Hills, IL), based on our previous study (Neha et al., 2018). The bottles remained completely submerged, except for the neck region, during the entire heating process. We assumed an even heating as the constant shaking of mix allowed for uniform heating by utilizing the headspace. The core temperature was continuously monitored using a temperature probe. The samples were then rapidly cooled in an ice bath before further analysis. Each experimental trial was done in the replicates of 3 and repeated 3 times. To enumerate intact cells, 25-g samples of spiked and pasteurized ice cream mix were drawn and suspended in $225 \mathrm{~mL}$ of PBS. In addition, $1 \mathrm{~g}$ of each spiked and pasteurized ice cream mix sample was directly pour plated using an esculinbased medium, modified Oxford agar (MOX; Remel, San Diego, CA), containing 1\% moxlactam selective supplement, to detect Listeria cells that might have survived the heat treatment. The plates were incubated at $37^{\circ} \mathrm{C}$ for $24 \mathrm{~h}$, and an extended incubation of $48 \mathrm{~h}$ was used to confirm the absence of growth. The incubated plates were observed for typical Listeria colonies; that is, small black colonies with a black halo (Park et al., 2014). To enumerate any potentially heat-injured cells of Listeria, we used an enrichment protocol as recommended in the US Food and Drug Administration's Bacteriological Analytical Manual (Hitchins et al., 2018). A 25-g portion of each laboratory-pasteurized spiked sample was suspended in $225 \mathrm{~mL}$ of buffered Listeria Enrichment Broth (BLEB, Oxoid/Thermo Scientific) and incubated for $4 \mathrm{~h}$ at $30^{\circ} \mathrm{C}$. Listeria selective enrichment supplements (acriflavin $\mathrm{HCl}$, nalidixic acid, and cycloheximide) were added after $4 \mathrm{~h}$ and the samples were further incubated at $30^{\circ} \mathrm{C}$. At 24 and 48-h intervals, BLEB enrichments were streaked on MOX agar and a chromogenic selective medium, Rapid'LMono (Bio-Rad Laboratories Inc., Hercules, CA) agar, to assess recovery of potentially heat-injured cells. The results were recorded as positive or negative based on the presence or absence of colonies on the selective media indicating recovery of potentially heatinjured cells of Listeria. The confirmation of Listeria at all stages of analysis was done using MALDI-TOF. To observe the air pockets and any entrapped Listeria cells within, the pre- and post-pasteurized spiked ice cream mix suspensions were placed on glass slides and airdried following a method previously described by Hassan et al. (2010), with a slight modification of overnight air drying. This process helped to retain the original distribution pattern of the spiked organisms in the mix matrix to the greatest extent possible. For scanning electron microscopy, the air-dried samples were sputter coated with a 10-nm-thick layer of $99 \%$ gold and observed at an accelerating voltage of $10 \mathrm{kV}$, maintaining a distance of $10 \mathrm{~mm}$ from the slide (Hitachi S-3400N, Hitachi America Ltd., Tarrytown, NY). For atomic force microscopy (AFM) studies, no pretreatment was 


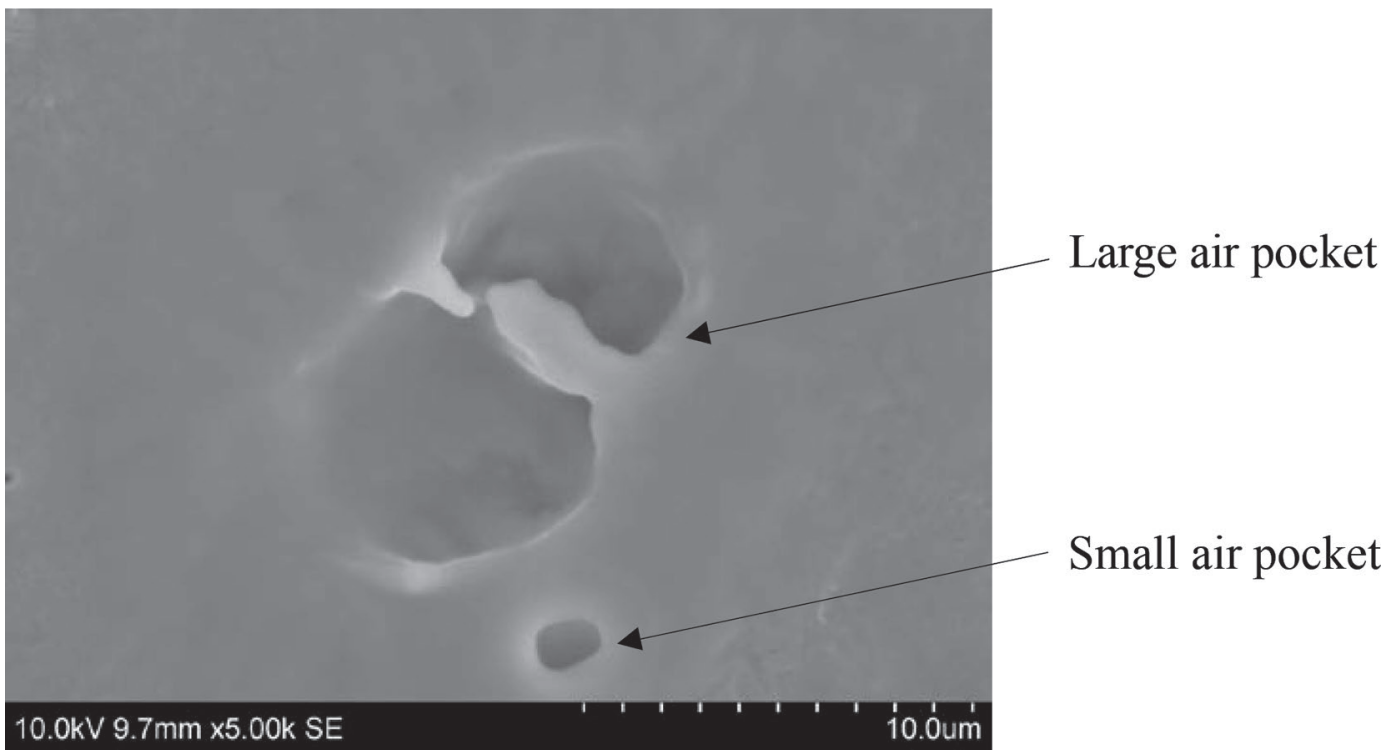

Figure 1. Scanning electron microscopy image showing large and small air pockets in the ice cream mix.

required for the air-dried samples. All observations were made using a commercial Agilent 5500 scanning probe microscope using a method previously standardized in our laboratory (Marka and Anand, 2018) and the Electrical Engineering department at South Dakota State University (Wu et al., 2018). Imaging was done in a tapping mode using an Si cantilever (TAP $300 \mathrm{Al}$; Budget Sensors, Watsonville, CA) AFM tip. The tip's first resonance (f1) frequency of $67 \mathrm{kHz}$ was fed into the first lock-in amplifier (LIA1). The vertical tip-sample separation was controlled from LIA1, which provided the error in the amplitude signal at f1 to the servo. This first lock-in amplifier was used for topographic and phase imaging. The tip used for measurement was a Multi75E-G budget sensor (Budget Sensors) with Cr/ $\mathrm{Pt}$ coating, a resonance frequency of $75 \mathrm{kHz}$, and force constant of $3 \mathrm{~N} / \mathrm{m}$. All images were stored in ASCII format, and Gwyddion software (http://gwyddion.net/

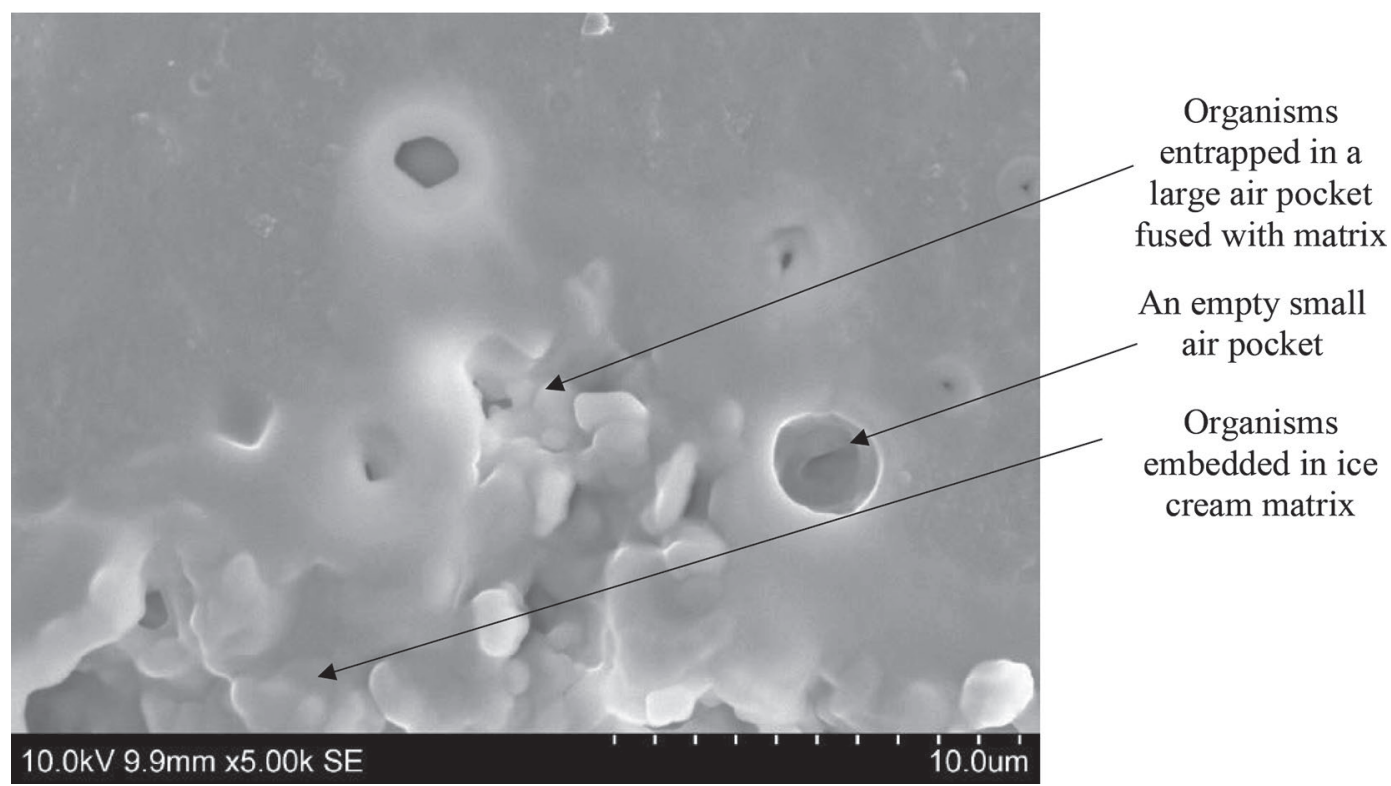

Figure 2. Listeria cells embedded in the matrix of spiked ice cream mix before heat treatment (scanning electron microscopy). Note the cells entrapped in large air pockets fused with matrix, whereas small air pockets are empty. 
) was used to process the images in 2-dimensional format. At least 3 scans were performed on each sample to observe the entrapped bacteria in air pockets.

Bacterial counts and chemical parameters obtained in the ice cream mix samples were comparable to those reported in our previous study (data not shown; Neha et al., 2018). Direct plating of heat-treated spiked ice cream mix samples did not show any Listeria cells (uninjured intact cells), which supports our previous report (Neha et al., 2018) and others, demonstrating that Listeria monocytogenes did not survive pasteurization of ice cream mix with a $\mathrm{D}_{79.4^{\circ} \mathrm{C}}$ value of $0.5 \mathrm{~s}$ (Bradshaw et al., 1987; Holsinger et al., 1992). Following the enrichment protocol as per the Bacteriological Analytical Manual (Hitchins et al., 2018), we detected a sporadic presence of some potentially heat-injured cells, especially after a prolonged enrichment of $48 \mathrm{~h}$. As reported previously, this could be due to sublethal damage of the cytoplasmic membrane, also known as structural damage (Hauben et al., 1996; Pagán and Mackey, 2000; Ritz et al., 2001), or due to damage of intracellular components, also known as physiological damage (Niven et al., 1999; Ritz et al., 2002).

The scanning electron micrographs helped us visualize the presence of several air pockets in the ice cream mix samples. In general, although most air pockets were small $(1-2 \mu \mathrm{m})$, some were larger $(4-8 \mu \mathrm{m}$; Figure 1). This variability in the size of air pockets could have been created during the handling stages of the mix. The size of the air pockets appeared to influence the extent of entrapment of Listeria cells, which explains the sporadic presence of potentially heat-injured cells in the spiked heat-treated mix. Figure 2 shows Listeria cells embedded in the matrix of spiked ice cream mix and entrapped within the larger air pocket, which is fused with the matrix. However, the smaller air pockets are empty. These observations indicate the possibility that larger air pockets within the ice cream mix may entrap intact Listeria cells in case cross contamination of mix occurred before heat treatment. This could have led to the sporadic presence of injured Listeria cells after exposure to heat treatment, as detected by the enrichment protocol. We cannot, however, rule out the possibility that the selective media enumeration missed some healthy cells in addition to not supporting the growth of some injured cells. However, the possibility that these cells were injured is more likely because most of the cells showed a delayed recovery and were detected only after $48 \mathrm{~h}$ of enrichment, and is not anticipated to be a function of low initial counts. We propose further investigation into the protective role of air pockets, possibly by altering their numbers in ice cream mix, for example by aeration. The scanning electron and atomic force micrographs of the spiked and heat-treated ice cream mix samples revealed the presence of some Listeria cells (as confirmed by MALDI-TOF) entrapped within the larger air pockets (Figures 3 and 4) but not observed in the surrounding matrix of spiked heat-treated mix. These observations supported the culture-based and MALDI-TOF data.

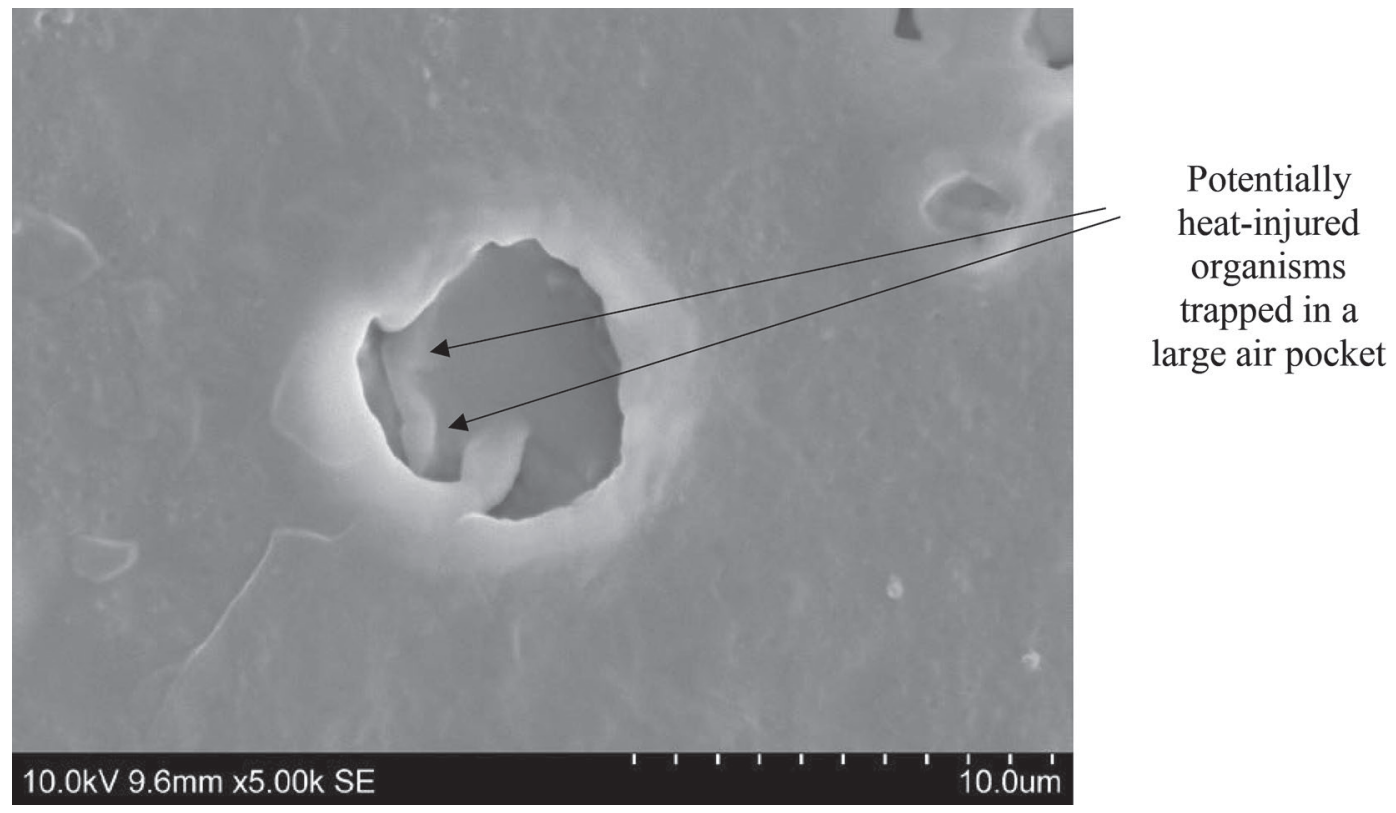

Figure 3. Listeria cells (potentially heat-injured) entrapped in the large air pocket of spiked ice cream mix after heat treatment (scanning electron microscopy). No cells are embedded in the matrix. 


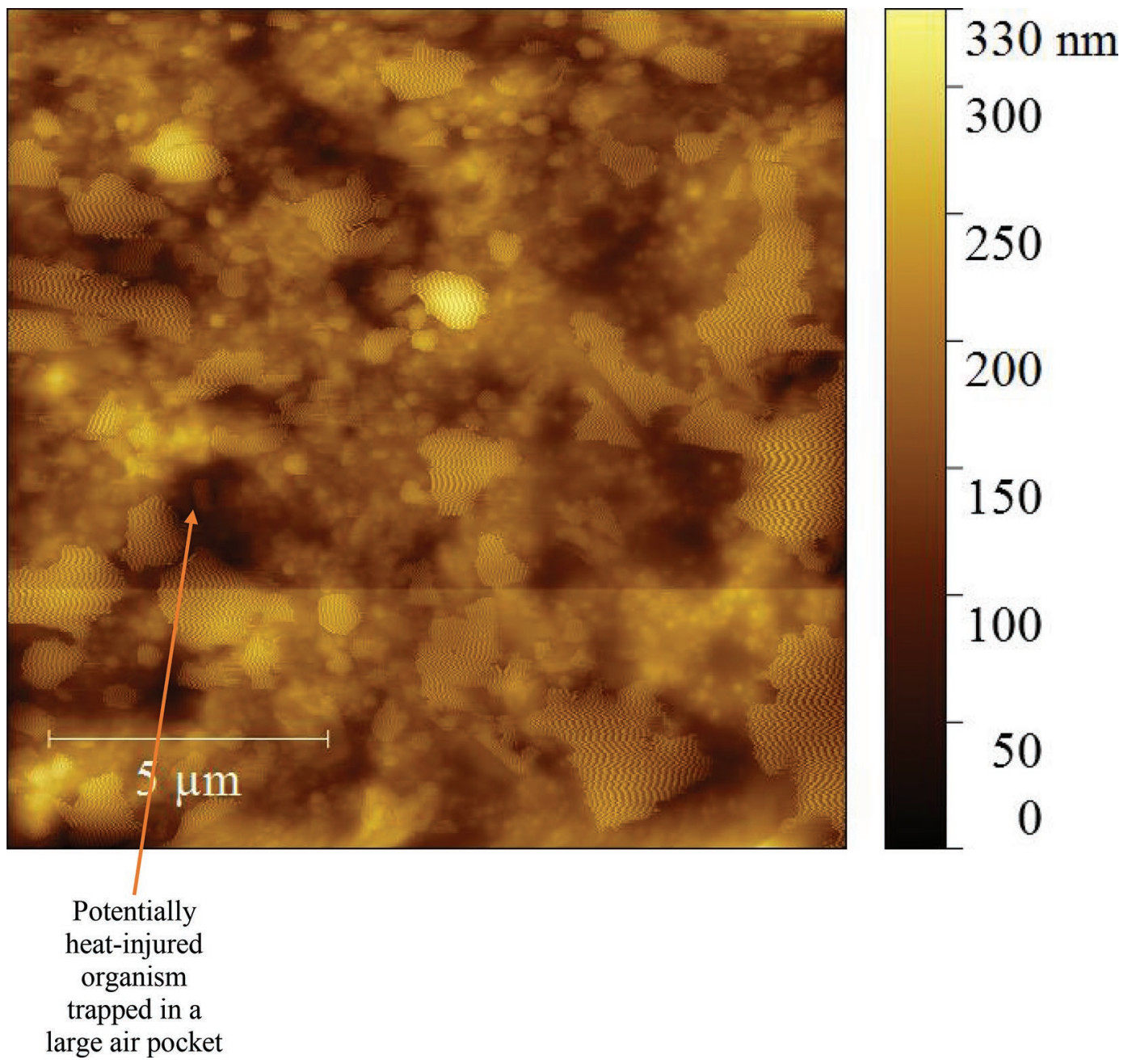

Figure 4. Listeria cells (potentially heat-injured) entrapped in the large air pocket of spiked ice cream mix after heat treatment (2-dimensional atomic force microscopy). No cells are embedded in the matrix.

The results suggest that it is likely that the Listeria cells entrapped within the larger air pockets might not have received adequate thermal effect, resulting in their detection as potentially heat-injured cells, as discussed above. This study thus provides another perspective around assessing Listeria risk, in addition to factors such as higher cross contamination levels, background microflora, product constituents, lipid-shielding effects, and entrapment in polymorphonucleocytes, as reviewed in our previous paper (Neha et al., 2018). These results should be considered preliminary, and further studies are necessary to understand the true implications of these findings.

\section{ACKNOWLEDGMENTS}

This work was financially supported by Midwest Dairy Foods Research Center (Brookings, SD). The au- thors also acknowledge the support of the Agricultural Experimentation Station, South Dakota State University, in conducting this study, and the Electrical Engineering Department, South Dakota State University, for helping conduct the scanning electron and atomic force microscopy work. The support of Brian Kraus and Suresh Sutariya (Wells Enterprises Inc., Le Mars, IA) in providing mix samples is also acknowledged.

\section{REFERENCES}

Bearns, R. E., and K. F. Girard. 1958. The effect of pasteurization on Listeria monocytogenes. Can. J. Microbiol. 4:55-61.

Besse, N. 2002. Influence of various environmental parameters and of detection procedures on the recovery of stressed $L$. monocytogenes: A review. Food Microbiol. 19:221-234.

Bradshaw, J. G., J. T. Peeler, J. J. Corwin, J. M. Hunt, and R. M. Twedt. 1987. Thermal resistance of Listeria monocytogenes in dairy products. J. Food Prot. 50:543-544.

CDC (Centers for Disease Control and Prevention). 2015. Multistate outbreak of Listeriosis linked to Blue Bell Creameries products 
(Final Update). https://www.cdc.gov/listeria/outbreaks/ice -cream-03-15/index.html.

Doyle, M. P., K. A. Glass, J. T. Beery, G. A. Garcia, D. J. Pollard, and R. D. Schultz. 1987. Survival of Listeria monocytogenes in milk during high-temperature, short-time pasteurization. Appl. Environ. Microbiol. 53:1433-1438.

Farber, J. M., G. Sanders, J. Speirs, J.-Y. Daoust, D. Emmons, and R. Mckellar. 1988. Thermal resistance of Listeria monocytogenes in inoculated and naturally contaminated raw milk. Int. J. Food Microbiol. 7:277-286.

FDA (Food and Drug Administration). 2015. Jeni's Splendid Ice Creams, LLC 8/9/16. Accessed Aug. 15, 2018. https://www.fda .gov/iceci/enforcementactions/warningletters/2016/ucm516395 .htm.

FDA (Food and Drug Administration). 2018. Fieldbrook Foods Corporation, announces an extension of voluntary recall of orange ice cream bars and chocolate coated vanilla ice cream bars for possible health risk. Accessed Apr. 12, 2018. https://www.fda.gov/Safety/ Recalls/ucm591923.htm.

Hassan, A. N., S. Anand, and M. Avadhanula. 2010. Microscopic observation of multispecies biofilm of various structures on whey concentration membranes. J. Dairy Sci. 93:2321-2329.

Hauben, K. J. A., E. Y. Wuytack, C. C. F. Soontjens, and C. W. Michiels. 1996. High-pressure transient sensitization of Escherichia coli to lysozyme and nisin by disruption of outer-membrane permeability. J. Food Prot. 59:350-355.

Hitchins, A. D., K. Jinneman, and Y. Chen. 2018. Detection of Listeria monocytogenes in foods and environmental samples, and enumeration of Listeria monocytogenes in foods. Chapter 10 in Bacteriological Analytical Manual (BAM). US Food and Drug Administration, White Oak. MD.

Holsinger, V. H., P. W. Smith, J. L. Smith, and S. A. Palumbo. 1992. Thermal destruction of Listeria monocytogenes in ice cream mix. J. Food Prot. 55:234-237.

Kozempel, M., N. Goldberg, E. R. Radewonuk, O. J. Scullen, and J. C. Craig. 2000. Rapid hot dog surface pasteurization using cycles of vacuum and steam to kill Listeria innocua. J. Food Prot. 63:457-461.

Li, M., A. Pradhan, W. Wang, and Y. Li. 2013. Prediction of Listeria innocua survival in fully cooked chicken breast products during postpackage thermal treatment. Poult. Sci. 92:827-835.

Lou, Y., and A. E. Yousef. 1999. Characteristics of Listeria monocytogenes important to food processors. Pages 131-225 in Listeria,
Listeriosis, and Food Safety. 2nd ed. E. T. Ryser and E. H. Marth ed. Marcel Dekker Inc., New York, NY.

Marka, S., and S. Anand. 2018. Feed substrate influence biofilm formation on reverse osmosis membranes and their cleaning efficiency. J. Dairy Sci. 101:84-95.

McMahon, C. M., C. Byrne, J. Sheridan, D. Mcdowell, I. Blair, and T. Hegarty. 2000. The effect of culture growth phase on induction of the heat shock response in Yersinia enterocolitica and Listeria monocytogenes. J. Appl. Microbiol. 89:198-206.

Neha, N., S. Anand, G. Djira, B. Kraus, and S. Sutariya. 2018. Listeria cross contamination levels in raw ice cream mix can serve as a predictor of their presence as potentially heat-injured cells. J. Dairy Sci. 101:9659-9669.

Niven, G. W., C. A. Miles, and B. M. Mackey. 1999. The effects of hydrostatic pressure on ribosome conformation in Escherichia coli: An in vivo study using differential scanning calorimetry. Microbiology 145:419-425.

Pagán, R., and B. Mackey. 2000. Relationship between membrane damage and cell death in pressure-treated Escherichia coli cells Differences between exponential and stationary phase cells and variation among strains. Appl. Environ. Microbiol. 66:2829-2834.

Park, S.-H., P.-S. Chang, S. Ryu, and D.-H. Kang. 2014. Development of a novel selective and differential medium for the isolation of Listeria monocytogenes. Appl. Environ. Microbiol. 80:1020-1025.

Ritz, M., J. Tholozan, M. Federighi, and M. Pilet. 2002. Physiological damages of Listeria monocytogenes treated by high hydrostatic pressure. Int. J. Food Microbiol. 79:47-53.

Ritz, M., J. L. Tholozan, M. Federighi, and M. F. Pilet. 2001. Morphological and physiological characterization of Listeria monocytogenes subjected to high hydrostatic pressure. Appl. Environ. Microbiol. 67:2240-2247.

Ryser, E. T., and E. H. Marth. 1999. Listeria, Listeriosis, and Food Safety. 2nd ed. Marcel Dekker Inc., New York, NY.

Wehr, H. M., and J. F. Frank. 2004. Standard Methods for the Examination of Dairy Products. 17th ed. American Public Health Association, Washington, DC.

Wu, F., B. Bahrami, K. Chen, S. Mabrouk, R. Pathak, Y. Tong, X. Li, T. Zhang, R. Jian, and Q. Qiao. 2018. Bias-dependent normal and inverted J-V hysteresis in perovskite solar cells. ACS Appl. Mater. Interfaces 10:25604-25613. 